\title{
Fiber optic bronchoscopy in patients with acute hypoxemic respiratory failure requiring noninvasive ventilation - a feasibility study
}

Hans Jörg Baumann ${ }^{1,2 \dagger}$, Hans Klose $^{2 \dagger}$, Marcel Simon ${ }^{1,2}$, Tarik Ghadban', Stephan A Braune', Jan K Hennigs ${ }^{2}$ and Stefan Kluge 1* $^{*}$

\begin{abstract}
Introduction: Noninvasive ventilation (NIV) is a standard procedure in selected patients with acute respiratory failure. Previous studies have used noninvasive ventilation to ensure adequate gas exchange during fiberoptic bronchoscopy in spontaneously breathing hypoxemic patients, thus avoiding endotracheal intubation. However, it is unknown whether bronchoscopy can be performed safely in patients with acute hypoxemic respiratory failure already in need of NIV prior to the decision for bronchoscopy.

Methods: We prospectively investigated 40 consecutive, critically ill, adult patients with acute hypoxemic respiratory failure (14 women, 26 men, age $61 \pm 15$ years, partial pressure for oxygen/fraction of inspired oxygen $\left(\mathrm{PaO}_{2} / \mathrm{FiO}_{2}\right)<300$ under noninvasive ventilation, Simplified Acute Physiology scores (SAPS II) $47 \pm 9.9$ points). All patients required noninvasive ventilation prior to the decision to perform bronchoscopy (median $10.5 \mathrm{~h}$; range 2.2 to 114). Blood gases, heart rate, blood pressure and ventilation were monitored before, during and up to 120 minutes after bronchoscopy.

Results: Bronchoscopy could be completed in all patients without subsequent complications. Oxygen saturation fell to $<90 \%$ in two patients (5\%), and the lowest value during the procedure was $84 \%$. The mean $\mathrm{PaO}_{2} / \mathrm{FiO}_{2}$ ratio improved from $176 \pm 54$ at baseline to $240 \pm 130(P<0.001)$ at the end of bronchoscopy and $210 \pm 79$ after 120 minutes. The transient mean partial pressure of carbon dioxide in the arterial blood $\left(\mathrm{PaCO}_{2}\right)$ increase was $9.4 \pm 8.1$ $\mathrm{mm} \mathrm{Hg}$. Four patients (10\%) required endotracheal intubation during the first eight hours after the procedure. Bronchoalveolar lavage yielded diagnostic information in 26 of $38(68 \%)$ patients.

Conclusions: In critically ill patients with acute hypoxemic respiratory failure requiring noninvasive ventilation, bronchoscopy can be performed with an acceptable risk. Since these patients per se have a high likelihood of subsequent endotracheal intubation due to failure of NIV, bronchoscopy should only be performed by experienced clinicians.
\end{abstract}

\section{Introduction}

Noninvasive ventilation (NIV) constitutes a cornerstone in the treatment of acute respiratory failure of various etiologies [1-3]. Some patients treated for acute respiratory failure in the intensive care unit will require diagnostic or therapeutic bronchoscopy. While bronchoscopy is generally considered a safe intervention [4], it is well

\footnotetext{
* Correspondence: skluge@uke.de

+ Contributed equally

'Department of Intensive Care Medicine, University Medical Center

Hamburg-Eppendorf, Martinistr. 52, Hamburg, 20246, Germany

Full list of author information is available at the end of the article
}

known that bronchoscopy and especially bronchoalveolar lavage (BAL) may induce significant hypoxemia [5]. Therefore, severe hypoxemia represents a contraindication for bronchoscopy unless it can be reversed by therapeutic interventions. Especially in hypoxemic patients the known benefits of the procedure have to be weighed against possible risks [6].

Small case series and few randomized controlled studies have suggested that NIV can prevent respiratory deterioration in spontaneously breathing hypoxemic patients undergoing bronchoscopy [7-13]. In these

\section{() Biomed Central}


studies noninvasive ventilatory support was purely initiated to facilitate bronchoscopy and the study population did not require NIV for hypoxemia at that point in time. However, it is unknown whether bronchoscopy can be performed with acceptable risk in patients with acute hypoxemic respiratory failure already in need of NIV prior to the decision for bronchoscopy. These patients represent a population with substantially more respiratory compromise than those from the previous studies mentioned above [7-13].

We, therefore, conducted a prospective study to assess the feasibility of fiberoptic bronchoscopy in critically ill patients already requiring NIV due to acute hypoxemic respiratory failure prior to the bronchoscopy procedure.

\section{Material and methods Study design}

The study was an observational, prospective cohort study. It was approved by the ethics committee of the chamber of physicians in Hamburg, Germany and was performed in accordance with the ethical standards laid down in the Declaration of Helsinki. Patients admitted between November 2007 and January 2010 to the Department of Intensive Care Medicine, University Medical Center Hamburg-Eppendorf were eligible for enrolment into the study. All participants or their legal representatives gave written informed consent.

\section{Study subjects}

The patient population included consecutive medical, neurological and surgical intensive care unit (ICU) patients. Inclusion criteria were: 1) acute hypoxemic respiratory insufficiency with consecutive hypoxemia, defined as $\mathrm{PaO}_{2} / \mathrm{FiO}_{2}<300$ under noninvasive ventilation, 2) requiring NIV prior to bronchoscopy, 3) requiring fiberoptic bronchoscopy for diagnostic or therapeutic reasons, 4) age $\geq 18$ years, and 5) informed consent. Patients in whom NIV was instituted purely to facilitate bronchoscopy were excluded. The decision both to initiate NIV and to perform a bronchoscopy was made by the attending intensivist on clinical grounds and in accordance with published guidelines [14]. Simplified acute physiology scores (SAPS II) were calculated using standard criteria [15]. Immunosuppression was defined as absolute neutrophil count $<1,000 / \mathrm{mL}$, immunosuppressive medication, organ transplantation, high dose chemotherapy during the past 60 days, or acquired immunodeficiency syndrome. Standard microbiological diagnostic measures prior to bronchoscopy included blood cultures and urinary antigen assay for Legionella. While sputum cultures were rarely used, additional serological studies were ordered in immunosuppressed patients as indicated.

\section{Noninvasive ventilation}

According to inclusion criteria, all patients were on NIV prior to and throughout the bronchoscopy procedure. ICU ventilators were used with the NIV option activated (Evita 4, Dräger, Germany). The ventilator mode was set to pressure support (CPAP/ASB) or pressure controlled mode (BIPAP). Inspiratory pressure was set in the range from 10 to $25 \mathrm{~cm} \mathrm{H}_{2} \mathrm{O}$ and positive end-expiratory pressure (PEEP) from 5 to $10 \mathrm{~cm} \mathrm{H}_{2} \mathrm{O}$ to achieve optimal ventilation and oxygenation. Ventilator settings were adjusted by the attending intensivists. Simple full-face masks (B+P, Neunkirchen-Seelscheid, Germany) were used as interfaces secured to the patient's face with elastic straps. The time from initiation of NIV to the bronchoscopy procedure was recorded. Following bronchoscopy all patients remained on noninvasive ventilatory support for at least two hours.

\section{Bronchoscopy procedure}

Before, during and after the bronchoscopy, the electrocardiogram, invasive blood pressure, pulse oximeter (Infinity Omega, Dräger, Germany) and ventilatory parameters $\left(\mathrm{FiO}_{2}\right.$, ventilator mode, in- and expiratory pressures, tidal volume, and respiratory rate) were continuously monitored. Arterial samples were drawn for blood gas analysis from the arterial line at baseline, at the end of the procedure with the bronchoscope still placed in the trachea, and 15, 30, 45, 60, and 120 minutes after removal of the bronchoscope. Ventilator settings were adjusted to optimize ventilatory support. The fraction of inspired oxygen $\left(\mathrm{FiO}_{2}\right)$ was increased to 1.0 after the baseline blood gas analysis was obtained and kept constant throughout the procedure. After completion of bronchoscopy, $\mathrm{FiO}_{2}$ was reduced to the level at which it was set prior to the procedure and adjusted to maintain an arterial saturation of oxygen $\left(\mathrm{SaO}_{2}\right)>90 \%$. Figure 1 shows the schedule of the study procedures. A swivel connector ( $\mathrm{T}$-adapter) was inserted between the ventilator tubing and the mask to allow the insertion of the endoscope (BF-P60, Olympus, Japan), see Figure 2. Sedation was achieved following clinical protocols using a combination of a single dose of 1 to $2 \mathrm{mg}$ midazolam i.v. and repetitive bolus applications of 10 to $20 \mathrm{mg}$ propofol i.v. every two to three minutes. Following application of lidocaine gel the bronchoscope was introduced nasally or orally. Topical anesthesia (5 ml lidocaine $0.8 \%$ ) was applied as a spray via the bronchoscope channel to the laryngeal, tracheal and bronchial mucosa.

All bronchoscopies were performed by experienced physicians (HJB, SAB, MS, HK, SK). The decision to perform a BAL was not part of the study and was, therefore, left to the discretion of the attending intensivist. The bronchoscope was wedged in the appropriate subsegmental ostium and $\mathrm{NaCl} 0.9 \%$ solution was 


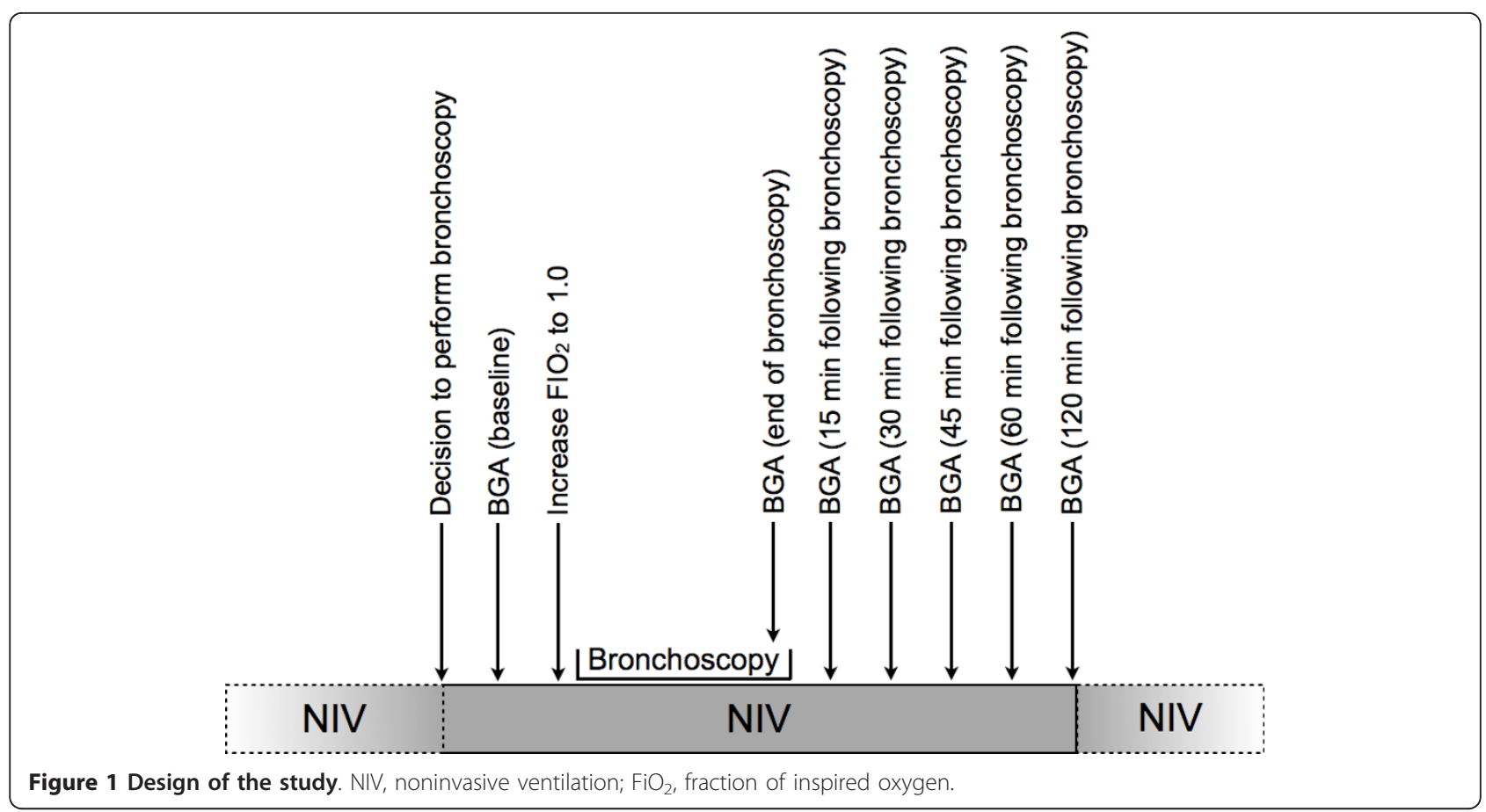

instilled in $20 \mathrm{ml}$ aliquots and gently aspirated. The amount of BAL fluid used was determined by the number of diagnostic tests ordered. BAL fluid was subjected to microscopic analysis and culturing as previously described $[16,17]$. The duration of bronchoscopy was defined as the time from insertion until removal of the bronchoscope from the tracheobronchial tree.

\section{Outcome}

Outcomes evaluated were intubation rate within eight hours of completion of bronchoscopy, intubation rate at

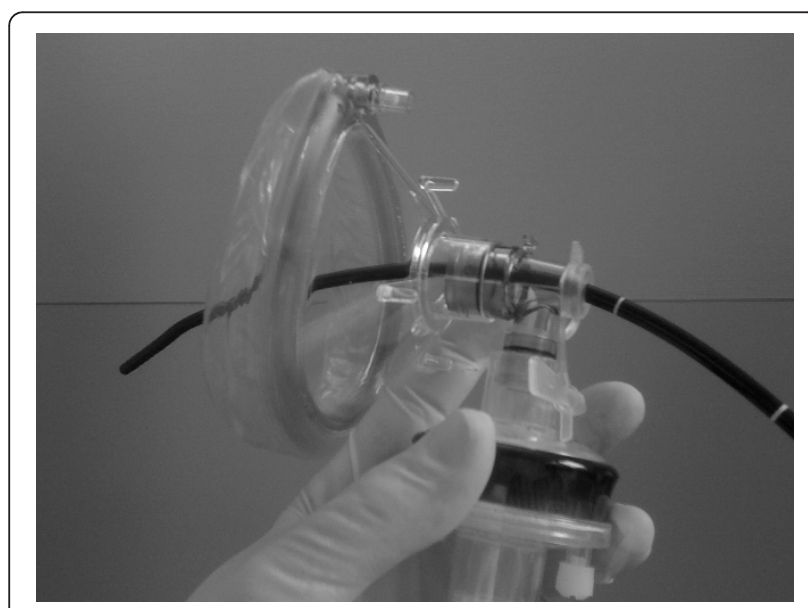

Figure 2 Bronchoscope inserted through swivel connector in the face mask. any time, length of ICU stay, and mortality. Intubation was considered a complication possibly related to bronchoscopy, if it occurred within eight hours of the procedure. This time span was adopted from previous studies $[11,18]$. The decision to intubate was left to the discretion of the attending intensivists in accordance with published guidelines [14]. In addition, patients were monitored for other adverse events (for example, hemorrhage, pneumothorax, hypotension, arrhythmia) that occurred during the procedure and in the 24 hours following the bronchoscopy, which could possibly be related to the procedure.

\section{Statistical analysis}

Results are expressed as the mean \pm standard deviation (SD) for continuous variables if normally distributed and as median with $95 \%$ confidence intervals if not. For repeated measures one-way ANOVA was used to detect significant differences between cardiorespiratory parameters at baseline, at the end of the bronchoscopy, and after $15,30,45,60$, and 120 minutes; $P$-values of 0.05 or less were considered significant.

\section{Results}

\section{Patient characteristics}

The study group consisted of 40 subjects. Patient characteristics are shown in Table 1. Median $\mathrm{PaO}_{2} / \mathrm{FiO}_{2}$ prior to initiation of NIV was $117 \pm 72$, mean $\mathrm{PaCO}_{2}$ was $40 \pm 13 \mathrm{~mm} \mathrm{Hg}$. The median duration of continuous NIV prior to bronchoscopy was $10.5 \mathrm{~h}$ (range 2.2 to 
$114 \mathrm{~h}$ ). At baseline $\mathrm{FiO}_{2}$ was $0.5 \pm 0.1$ and was increased to 1.0 in all patients during the bronchoscopy procedure. Within 30 minutes after the bronchoscopy mean $\mathrm{FiO}_{2}$ level returned to the baseline level.

Sedation was given to all patients: 27 received both midazolam $(2.0 \pm 0.8 \mathrm{mg})$ and propofol $(69 \pm 41 \mathrm{mg})$, while 13 patients $(33 \%)$ received propofol alone $(61 \pm 33$ $\mathrm{mg})$.

\section{Tolerance of the procedure}

The average duration of bronchoscopy was $7.8 \pm 5.5$ minutes (range 3.5 to 37.0 minutes). In all cases bronchoscopy was completed without subsequent complications. Two patients developed transient $\mathrm{SaO}_{2}$ values below $90 \%$ during the procedure, the minimum $\mathrm{SaO}_{2}$ was $84 \%$. Table 2 shows the course of cardiorespiratory parameters before, during and after the bronchoscopy. Significant changes from baseline were observed for $\mathrm{PaO}_{2} / \mathrm{FiO}_{2}, \mathrm{PaCO}_{2}$ and $\mathrm{pH}$ at the end of bronchoscopy, and 15 and 30 minutes after completion of the procedure, see Figure 3A. The average increase in $\mathrm{PaCO}_{2}$

Table 1 Patient characteristics, values given as mean \pm SD or no (\%)

\begin{tabular}{lc}
\hline No. of patients & 40 \\
Sex ratio (m/f) & $26 / 14$ \\
Age, years & $61 \pm 15$ \\
SAPS II score & $47 \pm 9.9$ \\
Thrombopenia < 50,000/mm ${ }^{3}$ & $6(15)$ \\
Immunosuppression & $21(53)$ \\
Use of vasopressors & $12(30)$ \\
Antibiotic therapy & $37(93)$ \\
Antimycotic therapy & $12(30)$ \\
Antiviral therapy & $5(13)$ \\
Underlying diagnosis & \\
$\quad$ Acquired immunodeficiency syndrome & $6(15)$ \\
$\quad$ Hematopoietic stem cell transplantation & $6(15)$ \\
COPD & $6(15)$ \\
Thoracic surgery & $4(10)$ \\
$\quad$ Solid cancer & $4(10)$ \\
$\quad$ Hematologic malignancy & $3(8)$ \\
Pulmonary embolism & $2(5)$ \\
Pulmonary fibrosis & $2(5)$ \\
Other & $7(18)$ \\
Indication for bronchoscopy & \\
Suspected lower airways infection & $23(58)$ \\
Suspected retention of secretions & $16(40)$ \\
Suspected stump insufficiency & $1(3)$ \\
Pressure support (CPAP/ASB) & \\
Pressure control (BIPAP) & $30(75)$ \\
\hline BPAP, biphasic postive aiway pressure; CoPD, cho & $10(25)$ \\
\hline
\end{tabular}

BIPAP, biphasic positive airway pressure; COPD, chronic obstructive pulmonary disease; CPAP/ASB, continuous positive airway pressure with assisted spontaneous breathing; SAPS II, Simplified acute physiology score II from baseline to end of bronchoscopy was $9.4 \pm 8.1 \mathrm{~mm}$ $\mathrm{Hg}$, see Figure 3B.

Baseline vs. post-bronchoscopy $\mathrm{PaO}_{2} / \mathrm{FiO}_{2}$ did not differ between patients who underwent bronchoscopy due to suspected lower airways infection $(189 \pm 53$ vs. $261 \pm$ $160)$ vs. patients with suspected retention of secretions $(159 \pm 52$ vs. $213 \pm 92)$.

The amount of sedation delivered was not related to the increase in $\mathrm{PaCO}_{2}$. Mean heart rate and arterial pressure did not change significantly during the procedure. No patient needed initiation or dose adjustments of vasopressors during the procedure. No other adverse events, such as hemorrhage, arrhythmia, or pneumothorax, were detected.

All but two patients remained on NIV until the end of the 120-minute period following bronchoscopy. The two patients stopped NIV after 60 minutes and breathed oxygen with flow rates of 5 and $10 \mathrm{~L} /$ minute. Both these patients had suspected lower airways infection as the indication to perform bronchoscopy.

\section{Results of fiberoptic bronchoscopy}

Table 3 shows the clinical and microbiological results of the bronchoscopy procedures.

\section{Outcome}

Four patients (10\%) had to be intubated in the pre-specified interval of eight hours following bronchoscopy. Underlying diagnoses were suspected pneumonia in AIDS, suspected pneumonia in leukemia, and suspected retention of secretions in two patients following thoracic surgery. These events were considered to be related to the bronchoscopy. None of them were hypercapnic at baseline, but their $\mathrm{PaO}_{2} / \mathrm{FiO}_{2}$ ratio under NIV was significantly lower than the rest of the study population (136 vs. $180, P<0.05)$. Two of the four patients died, one patient on the subsequent day due to cardiogenic shock, the other 25 days later. In addition, in the first 48 hours another patient died without being intubated due to progressive liver failure.

In total, intubation was necessary in $22(55 \%)$ patients. The median interval from bronchoscopy to intubation was $27.4 \mathrm{~h}$ (range 2.3 to $260 \mathrm{~h}, 95 \%$ CI 23.3 to $73.8 \mathrm{~h}$ ). Forty-eight hours after the bronchoscopy a total of 18 patients $(45 \%)$ were intubated. Overall ICU mortality was $37.5 \%$ (15/40), hospital mortality $43 \%$ (17/40).

\section{Discussion}

Our results demonstrate a low complication rate for fiberoptic bronchoscopy in critically ill patients with acute hypoxemic respiratory failure requiring noninvasive ventilation already prior to bronchoscopy. Only four patients needed endotracheal intubation during the first eight hours following bronchoscopy (10\%), a result which falls within acceptable range. 
Table 2 Cardiorespiratory parameters, values given as mean \pm SD

\begin{tabular}{|c|c|c|c|c|c|c|c|}
\hline & Baseline & End of bronchoscopy & 15 minutes & 30 minutes & 45 minutes & 60 minutes & 120 minutes \\
\hline $\begin{array}{l}\text { Heart rate } \\
\text { (beats/ } \\
\text { minute) }\end{array}$ & $99 \pm 18$ & $97 \pm 17$ & $97 \pm 17$ & $97 \pm 17$ & $95 \pm 18$ & $94 \pm 18$ & $92 \pm 17$ \\
\hline $\begin{array}{l}\text { MAP } \\
(\mathrm{mm} \mathrm{Hg})\end{array}$ & $88 \pm 18$ & $81 \pm 17$ & $83 \pm 17$ & $86 \pm 17$ & $84 \pm 18$ & $84 \pm 14$ & $83 \pm 14$ \\
\hline $\begin{array}{l}\text { Respiratory rate } \\
\text { (breaths/min) }\end{array}$ & $27 \pm 7$ & $27 \pm 8$ & $30 \pm 10$ & $29 \pm 9$ & $28 \pm 7$ & $28 \pm 8$ & $27 \pm 8$ \\
\hline $\begin{array}{l}\mathrm{PaO}_{2} / \\
\mathrm{FiO}_{2}\end{array}$ & $176 \pm 54$ & $240 \pm 130^{a}$ & $242 \pm 99^{a}$ & $215 \pm 76^{c}$ & $207 \pm 70$ & $199 \pm 68$ & $210 \pm 79$ \\
\hline $\begin{array}{l}\mathrm{PaCO}_{2} \\
(\mathrm{~mm} \mathrm{Hg})\end{array}$ & $43 \pm 14$ & $53 \pm 16^{a}$ & $50 \pm 15^{a}$ & $47 \pm 14^{c}$ & $45 \pm 13$ & $44 \pm 12$ & $42 \pm 13$ \\
\hline $\mathrm{pH}$ & $7.37 \pm 0.09$ & $7.30 \pm 0.08^{a}$ & $7.31 \pm 0.07^{a}$ & $7.34 \pm 0.08^{b}$ & $7.35 \pm 0.09$ & $7.36 \pm 0.09$ & $7.37 \pm 0.08$ \\
\hline
\end{tabular}

$a_{:} P<0.001$ compared to baseline

$b_{:}: P<0.01$ compared to baseline

c: $P<0.05$ compared to baseline

MAP, mean arterial pressure; $\mathrm{FiO}_{2}$, fraction of inspired oxygen; $\mathrm{PaCO}_{2}$, partial pressure of carbon dioxide in the arterial blood; $\mathrm{PaO}_{2}$, partial pressure of oxygen in the arterial blood

The main difference of our study population to that of pre-existing studies $[7-13,18,19]$ on bronchoscopy under noninvasive ventilatory support is that NIV had already been established in our patients irrespective of a

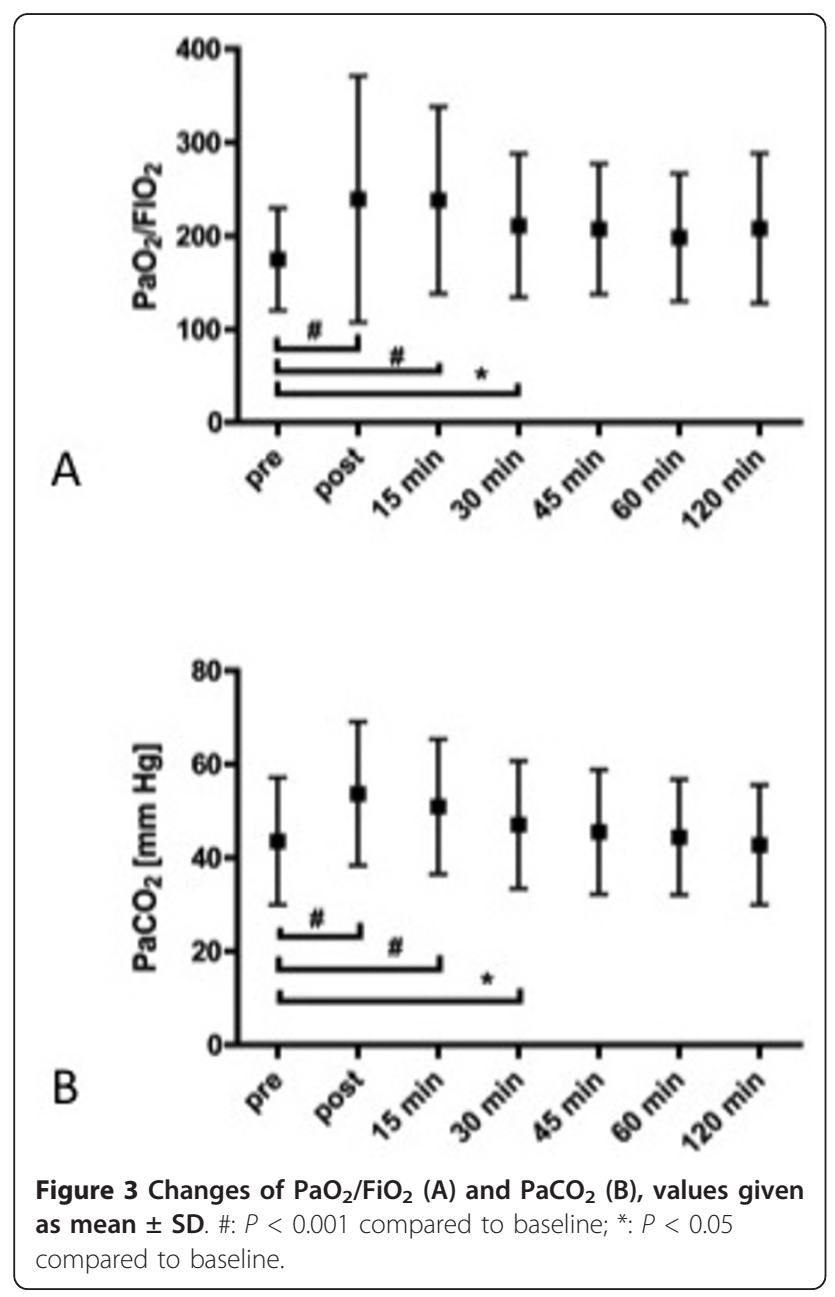

planned bronchoscopy. In the above mentioned previous studies NIV was initiated primarily to facilitate bronchoscopy. These differences of timing and reason for NIV characterize our study population as more critically ill in terms of hypoxemia than those of previous studies. This needs to be taken into consideration when interpreting the average $\mathrm{PaO}_{2} / \mathrm{FiO}_{2}$ ratio of $176 \pm 54$ in our study, since it was determined under conditions of NIV as opposed to the average $\mathrm{PaO}_{2} / \mathrm{FiO}_{2}$ ratios reported in the above mentioned studies, which were recorded in

Table 3 Results of fiberoptic bronchoscopy $(n=40)$

\begin{tabular}{|c|c|}
\hline No. of patients undergoing BAL & $38(95)$ \\
\hline Instilled volume during BAL (ml) & $110(108$ to 112$)$ \\
\hline Recovered BAL fluid (ml) & 38 (31 to 44$)$ \\
\hline \multicolumn{2}{|l|}{ Microbiolocial results } \\
\hline Candida species (colonisation) & $18(45)$ \\
\hline obligate or potentially pathogenic organisms & $25(66)$ \\
\hline Corynebacterium & $3(8)$ \\
\hline Staphylococcus aureus & $3(8)$ \\
\hline Escherichia coli & $2(5)$ \\
\hline Citrobacter species & $1(3)$ \\
\hline Enterobacter species & $1(3)$ \\
\hline Methicillin resistant Staph. aureus & $1(3)$ \\
\hline Neisseria species & $1(3)$ \\
\hline Proteus species & $1(3)$ \\
\hline Pseudomonas species & $1(3)$ \\
\hline Serratia marcescens & $1(3)$ \\
\hline Pneumocystis jirovecii & $4(11)$ \\
\hline Cytomegalovirus & $3(8)$ \\
\hline Herpes simplex virus & $3(8)$ \\
\hline Bronchialcarcinoma & $1(3)$ \\
\hline Treatment changes & $13(34)$ \\
\hline
\end{tabular}

Values given as number $(\%)$ or median $(95 \% \mathrm{Cl})$. Percent values of bronchoalveolar lavage (BAL) results refer to the group of 38 patients undergoing BAL 
spontaneously breathing patients. The mean $\mathrm{PaO}_{2} / \mathrm{FiO}_{2}$ of $117 \pm 72$ under spontaneous breathing prior to NIV initiation in our population represents one of the lowest value when compared to the existing literature.

The difference in disease severity is also reflected in a higher average SAPS II score $(47 \pm 9.9)$ of our population in comparison to that of previous studies. To our knowledge, the present study is the largest of its kind. Previous reports describe small numbers of patients under NIV requiring bronchoscopy $[7,10,18,20]$. However, our study, enrolling 40 patients, represents the most extensive and comprehensive report on critically ill patients requiring NIV due to acute respiratory failure and subsequent bronchoscopy.

It is difficult to determine whether the intubation of four patients $(10 \%)$ within the pre-specified period of eight hours following bronchoscopy was due to the natural clinical course of the underlying disease or related to the intervention itself. In several reports studying NIV-failure rates in patients with acute hypoxemic respiratory failure it was consistently shown that 1) this patient group has per se an intubation rate exceeding $50 \%$ and 2) once intubation is necessary this occurs within the first 24 to 48 hours in the majority of patients [21-24].

In comparison, our patients who had been on NIV for a median duration of 10.5 hours prior to bronchoscopy required an intubation in $45 \%$ of cases within the first 48 hours following bronchoscopy. Therefore, we believe that the reported intubation rate of $10 \%$ in the first eight hours after bronchoscopy falls within an acceptable range.

Surprisingly we did not find significant changes in the gas exchange before and after bronchoscopy between the two groups of patients with suspected lower airways infection versus suspected retained secretions. This observation might be explained by the small clinical differences of these two groups: While almost all patients $(38 / 40)$ underwent BAL, only very few patients showed relevant amounts of secretions in contrast to prior expectations before the procedure. The increase in $\mathrm{PaO}_{2} / \mathrm{FiO}_{2}$ ratio immediately after bronchoscopy cannot be explained by removal of secretions but may be attributable to other mechanisms.

Previously reported studies on bronchoscopy under NIV involved different methods of sedation. While Antonelli et al. exclusively used topical anaesthesia [7-9], others reported on sedation in subgroups of "agitated" patients [12]. Hilbert et al. described difficulties in performing bronchoscopy in severely hypoxemic patients without sedation and used analgosedation in all patients [18]. In our study, all patients received mild sedation using a combination of propofol and midazolam or propofol alone. We observed a mean increase of $\mathrm{PaCO}_{2}$ of $9.4 \pm 8.1 \mathrm{mmHg}$ that is in accordance with the results of studies on sedation during bronchoscopy in less critically ill and spontaneously breathing patients.

Our study has some limitations. First, we do not know whether performing bronchoscopy without sedation would have resulted in smaller increases of $\mathrm{PaCO}_{2}$ and possibly fewer intubations. As procedural sedation is the routine standard of care in our institution and no reports exist of bronchoscopy under NIV in similar patients, we considered it inappropriate to perform a controlled study.

Second, it should be emphasized that experienced clinicians performed all bronchoscopies. Therefore, our results may not be generalizable to other settings and, if less experienced physicians perform the procedures, a more cautious strategy may be appropriate. Third, as all results are influenced by the studied population, our conclusions are only applicable to patient populations with similar characteristics.

\section{Conclusions}

We found that bronchoscopy can be performed with acceptable risk in patients with severe acute hypoxemic respiratory failure already on noninvasive ventilatory support. Since these patients per se have a high risk of endotracheal intubation secondary to NIV failure, bronchoscopy should only be performed by clinicians experienced with bronchoscopy and endotracheal intubation in an environment with a high level of monitoring.

\section{Key messages}

- Noninvasive ventilation (NIV) facilitates bronchoscopy in patients with acute hypoxemic respiratory failure.

- Our study shows that even patients already requiring NIV due to acute hypoxemic respiratory failure may undergo bronchoscopy with acceptable risk.

- As these patients a priori have a high risk of NIV failure, only experienced staff should perform bronchoscopy in this patient population.

- In our study, BAL results revealed obligate or potentially pathogenic organisms in $25 / 38$ patients (66\%) and lead to treatment changes in 13/38 (34\%) of patients.

\section{Abbreviations}

BAL: bronchoalveolar lavage; BIPAP: biphasic positive airway pressure; CPAP/ ASB: continuous positive airway pressure with assisted spontaneous breathing; ICU: intensive care unit; NIV: noninvasive ventilation; $\mathrm{PaO}_{2} / \mathrm{FiO}_{2}$ : ratio of partial pressure for oxygen to fraction of inspired oxygen; PEEP: positive end-expiratory pressure; $\mathrm{SaO}_{2}$ : arterial oxygen saturation; SAPS II: Simplified Acute Physiology Score II; SD: standard deviation

\section{Acknowledgements}

The authors thank the nursing staff of the Department of Intensive Care Medicine and the bronchoscopy service of the University Medical Center 
Hamburg-Eppendorf, Germany. They also thank Liz Wager for editing the manuscript.

\section{Author details}

'Department of Intensive Care Medicine, University Medical Center Hamburg-Eppendorf, Martinistr. 52, Hamburg, 20246, Germany. ${ }^{2}$ Department of Respiratory Medicine, University Medical Center Hamburg-Eppendorf, Martinistr. 52, Hamburg, 20246, Germany

\section{Authors' contributions}

$\mathrm{HJB}, \mathrm{HK}, \mathrm{MS}, \mathrm{SB}, \mathrm{JKH}$ and SK have made substantial contributions to the conception and design of the study. HJB, HK, MS, SAB and SK performed the bronchoscopies. TG collected the data. HJB, TG and SK performed the analysis and interpretation of data. HJB, SAB and SK drafted the manuscript. All authors read and approved the final manuscript.

\section{Competing interests}

The authors declare that they have no competing interests.

Received: 19 February 2011 Revised: 10 July 2011

Accepted: 27 July 2011 Published: 27 July 2011

\section{References}

1. Nava S, Hill N: Non-invasive ventilation in acute respiratory failure. Lancet 2009, 374:250-259

2. Schönhofer B, Kuhlen R, Neumann P. Westhoff M, Berndt C, Sitter H: [Essentials from the non-invasive ventilation as treatment for acute respiratory insufficiency: new S3 guidelines]. Anaesthesist. 2008, 57:1091-1102, [Article in German].

3. Kluge S, Baumann HJ, Kreymann G: Intrahospital transport of a patient with acute exacerbation of chronic obstructive pulmonary disease under noninvasive ventilation. Intensive Care Med 2005, 31:886

4. Facciolongo N, Patelli M, Gasparini S, Lazzari Agli L, Salio M, Simonassi C, Del Prato B, Zanoni P: Incidence of complications in bronchoscopy. Multicentre prospective study of 20,986 bronchoscopies. Monaldi Arch Chest Dis 2009, 71:8-14.

5. Albertini RE, Harrell JH, Kurihara N, Moser KM: Arterial hypoxemia induced by fiberoptic bronchoscopy. JAMA 1974, 230:1666-1667.

6. British Thoracic Society: British Thoracic Society guidelines on diagnostic flexible bronchoscopy. Thorax 2001, 56(Suppl 1):i1-21.

7. Antonelli M, Pennisi MA, Conti G, Bello G, Maggiore SM, Michetti V, Cavaliere F, Proietti R: Fiberoptic bronchoscopy during noninvasive positive pressure ventilation delivered by helmet. Intensive Care Med 2003, 29:126-129.

8. Antonelli M, Conti G, Rocco M, Arcangeli A, Cavaliere F, Proietti R, Meduri GU: Noninvasive positive-pressure ventilation vs. conventional oxygen supplementation in hypoxemic patients undergoing diagnostic bronchoscopy. Chest 2002, 121:1149-1154

9. Antonelli M, Conti G, Riccioni L, Meduri GU: Noninvasive positive-pressure ventilation via face mask during bronchoscopy with BAL in high-risk hypoxemic patients. Chest 1996, 110:724-728.

10. Chiner E, Llombart M, Signes-Costa J, Andreu AL, Gomez-Merino E, Pastor E, Arriero JM: [Description of a new procedure for fiberoptic bronchoscopy during noninvasive ventilation through a nasal mask in patients with acute respiratory failure]. Arch Bronconeumol 2005, 41:698-701.

11. Maitre B, Jaber S, Maggiore SM, Bergot E, Richard JC, Bakthiari H, Housset B, Boussignac $G$, Brochard L: Continuous positive airway pressure during fiberoptic bronchoscopy in hypoxemic patients. A randomized doubleblind study using a new device. Am J Respir Crit Care Med 2000, 162:1063-1067

12. Heunks L, de Bruin C, van der Hoeven J, van der Heijden H: Non-invasive mechanical ventilation for diagnostic bronchoscopy using a new face mask: an observational feasibility study. Intensive Care Med 2009, 36:143-147.

13. Da Conceiçao M, Genco G, Favier JC, Bidallier I, Pitti R: [Fiberoptic bronchoscopy during noninvasive positive-pressure ventilation in patients with chronic obstructive lung disease with hypoxemia and hypercapnia]. Ann Fr Anesth Reanim 2000, 19:231-236.

14. Schönhofer B, Kuhlen R, Neumann P. Westhoff M, Berndt C, Sitter H: Clinical practice guideline: non-invasive mechanical ventilation as treatment of acute respiratory failure. Dtsch Arztebl Int 2008, 105:424-433.
15. Le Gall JR, Lemeshow S, Saulnier F: A new Simplified Acute Physiology Score (SAPS II) based on a European/North American multicenter study. JAMA 1993, 270:2957-2963.

16. Meduri GU, Chastre J: The standardization of bronchoscopic techniques for ventilator-associated pneumonia. Chest 1992, 102:557S-564S.

17. Baumann HJ, Kluge S, Balke L, Yekebas E, Izbicki JR, Amthor M, Kreymann G, Meyer A: Yield and safety of bedside open lung biopsy in mechanically ventilated patients with acute lung injury or acute respiratory distress syndrome. Surgery 2008, 143:426-433.

18. Hilbert G, Gruson D, Vargas F, Valentino R, Favier JC, Portel L, GbikpiBenissan G, Cardinaud JP: Bronchoscopy with bronchoalveolar lavage via the laryngeal mask airway in high-risk hypoxemic immunosuppressed patients. Crit Care Med 2001, 29:249-255.

19. Trachsel D, Erb TO, Frei FJ, Hammer J: Use of continuous positive airway pressure during flexible bronchoscopy in young children. Eur Respir $J$ 2005, 26:773-777.

20. Scala R, Naldi M, Maccari U: Early fiberoptic bronchoscopy during noninvasive ventilation in patients with decompensated chronic obstructive pulmonary disease due to community-acquired-pneumonia. Crit Care 2010, 14:R80.

21. Adda M, Coquet I, Darmon M, Thiery G, Schlemmer B, Azoulay E: Predictors of noninvasive ventilation failure in patients with hematologic malignancy and acute respiratory failure. Crit Care Med 2008, 36:2766-2772.

22. Schettino G, Altobelli N, Kacmarek RM: Noninvasive positive-pressure ventilation in acute respiratory failure outside clinical trials: experience at the Massachusetts General Hospital. Crit Care Med 2008, 36:441-447.

23. Antonelli M, Conti G, Moro ML, Esquinas A, Gonzalez-Diaz G, Confalonieri M, Pelaia P, Principi T, Gregoretti C, Beltrame F, Arcangeli A, Proietti R, Passariello M, Meduri GU: Predictors of failure of noninvasive positive pressure ventilation in patients with acute hypoxemic respiratory failure: a multi-center study. Intensive Care Med 2001, 27:1718-1728.

24. Antonelli M, Conti G, Esquinas A, Montini L, Maggiore SM, Bello G, Rocco M, Maviglia R, Pennisi MA, Gonzalez-Diaz G, Meduri GU: A multiple-center survey on the use in clinical practice of noninvasive ventilation as a first-line intervention for acute respiratory distress syndrome. Crit Care Med 2007, 35:18-25.

doi:10.1186/cc10328

Cite this article as: Baumann et al:: Fiber optic bronchoscopy in patients with acute hypoxemic respiratory failure requiring noninvasive ventilation - a feasibility study. Critical Care 2011 15:R179.

\section{Submit your next manuscript to BioMed Central and take full advantage of:}

- Convenient online submission

- Thorough peer review

- No space constraints or color figure charges

- Immediate publication on acceptance

- Inclusion in PubMed, CAS, Scopus and Google Scholar

- Research which is freely available for redistribution 